\title{
Profil Penggunaan Fall Risk Medicines pada Pasien Lanjut Usia di Instalasi Rawat Jalan Rumah Sakit Madiun
}

\author{
Profile of the use of Fall Risk Medicine in the Elderly Patients at Outpatient Department in Madiun \\ Hospital
}

Fita Rahmawati ${ }^{1 *}$, Nasikhatul Mustafidah², Lily Annisa ${ }^{2}$

1. Departemen Farmakologi dan Farmasi Klinik, Fakultas Farmasi, Universitas Gadjah Mada, Yogyakarta

2. Program Pascasarjana Farmasi Klinik, Fakultas Farmasi, Universitas Gadjah Mada, Yogyakarta

Submitted: 19-04-2019 Revised: 19-06-2019 Accepted: 19-06-2019

Korespondensi : Fita Rahmawati : Email : malihahanun@yahoo.com

\begin{abstract}
ABSTRAK
Penggunaan obat tertentu diketahui merupakan faktor ekstrinsik risiko jatuh pada lanjut usia (lansia) karena dapat menyebabkan hipotensi postural, sedasi, pusing, lemas, mengantuk, kelemahan otot, dan efek samping lainnya. Penelitian ini bertujuan untuk mengetahui profil penggunaan obat yang berpotensi menyebabkan jatuh (fall risk medicines) pada lansia. Penelitian ini menggunakan rancangan deskriptif cross-sectional. Pengambilan data dilakukan pada dua rumah sakit di Kota Madiun (RSUD Dr. Soedono Madiun dan RSUD Kota Madiun) di Poliklinik Syaraf dan Penyakit Dalam. Teknik purposive sampling digunakan untuk menentukan sampel penelitian. Data bersumber dari rekam medis pasien dan dari riwayat pengambilan obat di Instalasi Farmasi bulan Mei sampai dengan Oktober 2018. Hasil penelitian menunjukkan terdapat 343 pasien (64,11\%) dari 535 pasien yang terlibat dalam penelitian menggunakan fall risk medicines (FRM). Tiga golongan FRM yang sering diresepkan adalah antihipertensi $52,71 \%$ (282 pasien), antikonvulsan 20,19\% (108 pasien), dan benzodiazepin 10,47\% (56 pasien). Sejumlah 46,54 \% (249 pasien) menggunakan FRM yang termasuk dalam kategori risiko rendah (Medication Fall Risk Score 1-5), dan sebanyak 17,57\% (94 pasien) menggunakan FRM dalam risiko tinggi (Medication Fall Risk Score $\geq 6$ ). Jumlah pengguna 1 obat FRM sebesar 24,86\% (133 pasien), diikuti 2 obat sebesar 19,07\% (102 pasien). Dari hasil penelitian ini diketahui penggunaan obat yang menyebabkan risiko jatuh pada lansia cukup tinggi, sehingga perlu dipertimbangkan risiko dan manfaat penggunaannya untuk mencegah kejadian jatuh pada lansia.

Kata kunci: profil, fall risk medicines, lansia.
\end{abstract}

\section{ABSTRACT}

The use of certain drugs is known to be an extrinsic factor the risk of falling in the elderly (elderly) because it can cause postural hypotension, sedation, dizziness, weakness, drowsiness, muscle weakness, and other side effects. This study aims to determine the profile of drug use that have the potential to fall in the elderly. This study used a cross-sectional descriptive design with purposive sampling technique. The study was carried out at two regional hospitals in Madiun (RSUD Dr. Soedono Madiun and RSUD Kota Madiun). The data is sourced from the outpatient's medical record of Neurology and Internal Medicine clinics and from the medication record in the Pharmacy Installation from May to October 2018. The results showed that there were 343 patients $(64.11 \%)$ out of 535 patients involved in the study using fall risk medicines (FRM). Three FRM groups that were often prescribed were antihypertensive $52.71 \%$ (282 patients), anticonvulsants $20.19 \%$ (108 patients), and benzodiazepines $10.47 \%$ (56 patients). A number of 46.54\% (249 patients) used FRM included in the low-risk category (Medication Fall Risk Score 1-5), and as many as $17.57 \%$ (94 patients) were included in high risk (Medication Fall Risk Score $\geq 6$ ). The elderly that use 1 FRM was $24.86 \%$ (133 patients), followed by 2 drugs was 19.07\% (102 patients). The results of this study realized that the use of fall risk medicines in the elderly is quite high, so it is necessary to weigh the risks and benefits of its use to prevent falls in the elderly.

Keywords: profile, fall risk medicines, the elderly.

\section{PENDAHULUAN}

Populasi Lansia (lanjur usia) di Indonesia semakin meningkat tiap tahunnya, pada tahun 2017 jumlahnya mencapai 23,4 juta jiwa atau $8,97 \%$ dari seluruh penduduk Indonesia. Angka kesakitan pada lansia 
di Indonesia cukup besar yaitu tiap 100 lansia terdapat 27 lansia yang sakit ${ }^{1}$. Dengan adanya gangguan kesehatan tersebut menyebabkan lansia mengkonsumsi obat. Akan tetapi penggunaan obat merupakan salah satu faktor ekstrinsik risiko jatuh². Diketahui bahwa prevalensi jatuh karena faktor medik (gangguan kesehatan dan penggunaan obat) adalah sebesar $18 \%{ }^{3}$.

Golongan obat yang diketahui dapat menyebabkan jatuh (falls risk medicines/FRM) antara lain analgesik termasuk opioid, antipsikotik, antikonvulsan, benzodiazepin, antihipertensi, obat jantung, antiaritmia, antiparkinson, dan diuretik ${ }^{2,4}$. Obat-obat tersebut dikelompokkan dalam level risiko tertentu oleh Ganz dkk. (2013) yang dikenal sebagai Medication Fall Risk Score (MFRS). Nilai dari MFRS digunakan untuk mengetahui potensi risiko jatuh karena penggunaan obat ${ }^{4}$.

Di Indonesia informasi terkait penggunaan obat yang berpotensi menyebabkan jatuh pada lansia masih sangat terbatas. Hal ini perlu mendapat perhatian dari para tenaga kesehatan sebagai upaya pencegahan jatuh dan cedera pada lansia. Penelitian ini bertujuan untuk mengetahui profil penggunaan obat yang berpotensi menyebabkan jatuh (fall risk medicines) pada lansia.

\section{METODE}

\section{Design penelitian}

Penelitian ini merupakan penelitian deskriptif cross-sectional. Pengambilan data dilakukan di poliklinik Syaraf dan Penyakit Dalam pada dua rumah sakit pemerintah di kota Madiun yaitu RSUD Dr. Soedono Madiun dan RSUD Kota Madiun.

\section{Subyek penelitian dan tehnik sampling}

Pengambilan sampel dilakukan menggunakan teknik purposive sampling. Sejumlah 535 pasien lansia terlibat dalam penelitian ini dengan kriteria inklusi: pasien berusia $\geq 60$ tahun, merupakan pasien kunjungan ulang rawat jalan, dan ada riwayat pengambilan obat di Instalasi Farmasi. Kriteria eksklusi: pasien dengan data rekam medis dan riwayat pengobatan tidak lengkap/tidak terbaca.

Data bersumber dari rekam medis pasien dan riwayat pengambilan obat di Instalasi Farmasi. Data dari rekam medis meliputi usia, jenis kelamin, berat badan, tinggi badan, dan diagnosa pasien. Data penggunaan obat pasien dari riwayat pengambilan obat pada periode bulan Mei sampai dengan Oktober 2018.

\section{Analisis hasil}

Hasil analisa data disajikan dalam bentuk persentase. Hasil penelitian ini meliputi karakteristik pasien lansia (umur, jenis kelamin, indeks massa tubuh/IMT, dan diagnosa) dan karakteristik fall risk medicines (FRM) yang digunakan (golongan obat, jenis obat, skor MFRS dan jumlah penggunaan obat FRM).

\section{Perhitungan skor MFRS}

Berdasarkan data riwayat pengobatan, selanjutnya penggunaan obat dikelompokkan sesuai dengan Medication Fall Risk Score (MFRS). MFRS membagi falls risk medicines menjadi 3 level skor yaitu:

1. Skor 3 (level resiko tinggi) meliputi: analgetik opioid, antipsikotik, antikonvulsan, benzodiazepin, dan sedatif-hipnotik non-benzodiazepine.

2. Skor 2 (level resiko sedang) meliputi: antidepresan, antihipertensi, obat jantung, antiaritmia.

3. Skor 1 (level resiko rendah) meliputi: diuretik

Skor MFRS total adalah penjumlahan dari nilai skor tiap falls risk medicines yang digunakan oleh pasien

\section{Persetujuan etik}

Penelitian ini disetujui oleh The Medical and Health Research Ethics Committee (MHREC) Fakultas Kedokteran Universitas Gadjah Mada dengan nomor KE/KF/1116/EC/2018.

\section{HASIL DAN PEMBAHASAN}

Karakteristik pasien lansia pada penelitian ini tertera pada Tabel I. Sejumlah $64,11 \%$ (343 pasien) menggunakan obat yang 
Fita Rahmawati, et al

Tabel I. Karakteristik Pasien Lansia di Rumah Sakit Madiun

\begin{tabular}{|c|c|c|c|c|c|c|c|}
\hline \multicolumn{2}{|c|}{ Karaktersitik } & \multicolumn{2}{|c|}{$\begin{array}{c}\text { Pakai FRM } \\
\mathrm{n}=343(64,11 \%)\end{array}$} & \multicolumn{2}{|c|}{$\begin{array}{c}\text { Tidak Pakai FRM } \\
\text { n=192 }(35,89 \%)\end{array}$} & \multicolumn{2}{|c|}{$\begin{array}{c}\text { Total } \\
\mathrm{N}=535(100 \%)\end{array}$} \\
\hline Usia & $>=80$ (lansia tua) & 23 & $(4,30 \%)$ & 18 & $(3,36 \%)$ & 41 & $7,66 \%$ \\
\hline \multirow[t]{2}{*}{ (tahun) } & 70-79 (lansia madya) & 115 & $(21,50 \%)$ & 51 & $(9,53 \%)$ & 166 & $31,03 \%$ \\
\hline & 60-69 (lansia muda) & 205 & $(38,32 \%)$ & 123 & $(22,99 \%)$ & 328 & $61,31 \%$ \\
\hline Jenis & Perempuan & 194 & $(36,26 \%)$ & 112 & $(20,93 \%)$ & 306 & $57,20 \%$ \\
\hline Kelamin & Laki-Laki & 149 & $(27,85 \%)$ & 80 & $(14,95 \%)$ & 229 & $42,80 \%$ \\
\hline Indek Masa & Obesitas & 16 & $(2,99 \%)$ & 4 & $(0,75 \%)$ & 20 & $3,74 \%$ \\
\hline Tubuh & Overweight & 60 & $(11,21 \%)$ & 42 & $(7,85 \%)$ & 102 & $19,07 \%$ \\
\hline \multirow[t]{2}{*}{$(\mathrm{Kg} / \mathrm{m} 2)$} & Normal & 255 & $(47,66 \%)$ & 135 & $(25,23 \%)$ & 390 & $72,90 \%$ \\
\hline & Underweight & 12 & $(2,24 \%)$ & 11 & $(2,06 \%)$ & 23 & $4,30 \%$ \\
\hline \multirow[t]{5}{*}{ Komorbid } & Hipertensi & 189 & $(35,33 \%)$ & 52 & $(9,72 \%)$ & 241 & $(45,05 \%)$ \\
\hline & Diabetes Mellitus & 147 & $(27,48 \%)$ & 49 & $(9,16 \%)$ & 196 & $(36,64 \%)$ \\
\hline & $\begin{array}{l}\text { Cerebrovascular } \\
\text { disease }\end{array}$ & 117 & $(21,87 \%)$ & 60 & $(11,21 \%)$ & 177 & $(33,08 \%)$ \\
\hline & $\begin{array}{l}\text { Jantung (gagal } \\
\text { jantung kronik / } \\
\text { Penyakit Jantung } \\
\text { Koroner) }\end{array}$ & 65 & $(12,15 \%)$ & 11 & $(2,06 \%)$ & 76 & $(14,21 \%)$ \\
\hline & Low Back Pain & 26 & $(4,86 \%)$ & 22 & $(4,11 \%)$ & 48 & $(8,97 \%)$ \\
\hline
\end{tabular}

FRM: Fall Risk Medicines

termasuk dalam kategori fall risk medicines (FRM). Hasil ini lebih tinggi dibanding hasil penelitian di New York dimana sebesar 44\% lansia mendapatkan setidaknya 1 fall risk medicine ${ }^{5}$.

Secara umum sebagian besar pasien termasuk dalam kategori lansia muda (60-69 tahun) sebanyak $61,31 \%$ (328 pasien). Rerata usia pasien lansia adalah $68,01 \pm 6,26$ tahun dengan rentang usia 60-93 tahun. Hal ini sesuai dengan hasil laporan Badan Pusat Statistik tahun 2018, dimana lansia di Indonesia didominasi oleh lansia muda $(63 \%)^{6}$.

Dari tabel I juga terlihat bahwa lansia perempuan mendominasi sampel penelitian sebanyak 57,20\% (306 pasien). Hasil penelitian sejalan dengan hasil laporan Badan Pusat Statistik tahun 2018, dimana lansia di Indonesia didominasi oleh lansia perempuan $(52,52 \%)^{6}$. Proporsi lansia perempuan lebih besar daripada lansia laki-laki karena usia harapan hidup (UHH) pada perempuan lebih besar dibanding lansia laki-laki yaitu sebesar
72,70 tahun, sedangkan UHH lansia laki-laki 68,82 tahun ${ }^{6}$. Data ini juga dapat menggambarkan kesadaran berobat pada lansia perempuan lebih besar daripada lansia laki-laki dimana berdasarkan hasil sensus Badan Pusat Statistik tahun 2017 menunjukkan kesadaran berobat pada lansia perempuan sebesar $52,87 \%$, sedangkan pada lansia laki-laki sebesar $51,93 \% 1$.

Sebagian besar $(72,90 \%)$ pasien lansia mempunyai indek masa tubuh (IMT) normal dengan rerata $22,96 \pm 3,34$, yang menunjukkan asupan nutrisi yang cukup. IMT juga merupakan faktor yang berkorelasi terhadap keseimbangan pada lansia sehingga berkaitan dengan risiko jatuh ${ }^{7}$. Lansia dengan obesitas mempunyai risiko jatuh $31 \%$ lebih tinggi dibanding pasien lansia yang tidak obesitas ${ }^{8}$.

Kondisi kesehatan merupakan salah satu faktor risiko jatuh pada lansia $2,9,10$. Badan Pusat Statistik tahun 2017 menyebutkan $26,72 \%$ lansia mengalami sakit atau gangguan kesehatan. Hasil riset oleh kementerian kesehatan tahun 2018 diketahui gangguan 
Tabel II. Profil Penggunaan Fall Risk Medicines pada Pasien Lansia di Rumah Sakit Madiun

\begin{tabular}{llcc}
\hline & Karaktersitik & Jumlah Pasien & $\mathbf{\%}$ \\
\hline Golongan & Cardiovaskuler +Nervous system drugs & 81 & $15,14 \%$ \\
& Obat Kardiovaskuler & 209 & $39,07 \%$ \\
& Obat Susunan Saraf Pusat & 53 & $9,91 \%$ \\
& Tidak & 192 & $35,89 \%$ \\
Medication Fall Risk & $\geq 6$ & 94 & $17,57 \%$ \\
Score (MFRS) & $1-5$ & 249 & $46,54 \%$ \\
& 0 & 192 & $35,89 \%$ \\
Jumlah Penggunaan & $>=5$ & 10 & $1,87 \%$ \\
Fall Risk Medicines & 4 & 38 & $7,10 \%$ \\
& 3 & 60 & $11,21 \%$ \\
& 2 & 102 & $19,07 \%$ \\
& 1 & 133 & $24,86 \%$ \\
& 0 & 192 & $35,89 \%$ \\
\hline
\end{tabular}

kesehatan terbesar pada lansia $(>55 \%)$ adalah hipertensi ${ }^{11}$. Hasil riset tersebut sejalan dengan hasil penelitian ini, dimana hipertensi merupakan diagnosa terbesar yaitu sebanyak $45,05 \%$ (241 pasien). Pada penelitian ini jenis penyakit yang potensial menyebabkan jatuh yaitu diabetes mellitus $36,64 \%$ (196 pasien), cerebrovascular disease $33,08 \%$ (177 pasien), dan penyakit jantung $14,21 \%$ (76 pasien).

Kelompok pasien yang menggunakan fall risk medicines (FRM) didominasi oleh lansia muda (60-69 tahun), lansia perempuan (36,26\%, 194 pasien) dengan komorbid hipertensi (35,33\%, 189 pasien). Hal ini sejalan dengan hasil riset dari kementerian kesehatan dimana hipertensi merupakan komorbid terbanyak pada lansia ${ }^{11}$, dengan prevalensi pada perempuan lebih besar daripada lakilaki ${ }^{12,13}$.

Penggunaan fall risk medicines (FRM) juga merupakan salah satu faktor risiko untuk jatuh. Dari penelitian-penelitian sebelumnya telah diketahui beberapa golongan obat merupakan faktor risiko jatuh pada lansia2,1416. Terlihat dari tabel II sebagian besar pasien menggunakan FRM yang termasuk dalam kategori risiko rendah (Medication Fall Risk Score 1-5) sebanyak 46,54\% (249 pasien). Pasien yang berisiko tinggi (Medication Fall Risk Score $\geq 6)$ sebanyak 94 pasien $(17,57 \%)$ yang harus dikonfirmasi lebih lanjut dengan penilaian risiko jatuh secara klinis. Hal tersebut untuk mencegah terjadinya jatuh pada pasein ${ }^{4}$.

Dari tabel II juga terlihat jumlah fall risk medicines (FRM) yang digunakan pasien berkisar 1-7 obat, namun didominasi oleh penggunaan 1 jenis FRM sebesar 24,86\%, diikuti 2 obat sebesar $19,07 \%$ dan FRM $\geq 5$ sebesar $1,87 \%$. Jumlah obat yang digunakan berpengaruh terhadap risiko jatuh seperti pada penelitian sebelumnya oleh Pratt, dimana penggunaan 3-4 FRM dapat meningkatkan risiko dua kali lipat untuk hospitalisasi karena jatuh pada lansia ${ }^{17}$.

Pada penelitian ini fall risk medicines (FRM) dibagi dalam dua kategori besar yaitu obat kardiovaskuler dan obat yang bekerja pada susunan saraf pusat. Profil golongan FRM dapat dilihat pada tabel III. FRM golongan obat kardiovaskuler digunakan oleh 290 pasien $(54,21 \%$ ) yang didominasi oleh obat antihipertensi (282 pasien). Obat-obat tersebut dapat menyebabkan jatuh antara lain melalui mekanisme hipotensi postural, sedasi, pusing, lemas, penurunan kewaspadaan, mengantuk, kelemahan otot, dan efek samping lainnya ${ }^{2}$. Obat kardiovaskuler yang signifikan berhubungan dengan jatuh berdasarkan penelitian sebelumnya yaitu loop-diuretik (OR 1,36 95\%CI 1,13-1,57) dan obat digitalis (OR 1,60 95\%CI 1,08-2,36) ${ }^{18}$. 
Tabel III. Profil Golongan Fall Risk Medicines pada Pasien Lansia di Rumah Sakit Madiun

\begin{tabular}{lcc}
\hline \multicolumn{1}{c}{ Golongan } & Jumlah pasien & $\mathbf{\%} \mathbf{( N = 5 3 5 )}$ \\
\hline Obat Kardiovaskuler & $\mathbf{2 9 0}$ & $\mathbf{5 4 , 2 1 \%}$ \\
Antihipertensi & 282 & $52,71 \%$ \\
Diuretik & 50 & $9,35 \%$ \\
Obat Jantung & 26 & $4,86 \%$ \\
Obat Susunan Saraf Pusat & $\mathbf{1 3 4}$ & $\mathbf{2 5 , 0 5 \%}$ \\
Antikonvulsan & 108 & $20,19 \%$ \\
Benzodiazepin & 56 & $10,47 \%$ \\
Antidepresan & 41 & $7,66 \%$ \\
Analgesik/ Opioids & 8 & $1,50 \%$ \\
Non-Benzodiazepin & 4 & $0,75 \%$ \\
\hline
\end{tabular}

Tabel IV. Profil Jenis Fall Risk Medicines pada Pasien Lansia di Rumah Sakit Madiun

\begin{tabular}{|c|c|c|}
\hline Nama Obat & $\mathrm{n}$ & $\%(\mathrm{~N}=535)$ \\
\hline \multicolumn{3}{|l|}{ Obat Kardiovaskuler } \\
\hline Amlodipin & 163 & $30,47 \%$ \\
\hline Bisoprolol & 68 & $12,71 \%$ \\
\hline Candesartan & 57 & $10,65 \%$ \\
\hline Valsartan & 42 & $7,85 \%$ \\
\hline Furosemid & 39 & $7,29 \%$ \\
\hline \multicolumn{3}{|l|}{ Obat Susunan Saraf Pusat } \\
\hline Gabapentin & 101 & $18,88 \%$ \\
\hline Diazepam & 50 & $9,35 \%$ \\
\hline Amitriptyline & 41 & $7,66 \%$ \\
\hline Tramadol & 6 & $1,12 \%$ \\
\hline Alprazolam & 4 & $0,75 \%$ \\
\hline
\end{tabular}

Obat yang bekerja pada susunan saraf pusat digunakan oleh 134 pasien (25,05\%), dan didominasi oleh antikonvulsan yang digunakan oleh 108 pasien $(20,19 \%)$. Penggunaan obat-obat tersebut berdasar penelitian sebelumnya berhubungan dengan risiko jatuh. Penelitian Masud dkk., (2013) menyebutkan obat-obat yang berhubungan dengan resiko jatuh yaitu antidepresan (OR 2,8 95\%CI 1,9-4,1), antiepilepsi (OR 2,8 95\%CI 1,5-5,1), opioid (OR 2,4 95\%CI 1,5-3,7), dan ansiolitik/hipnotik (OR 1,5 95\%CI 0,9-2,6) ${ }^{19}$. Studi metaanalisis pada tahun 2011 juga menyatakan penggunaan obat psikoropik berhubungan dengan risiko jatuh sebesar 1,78 (95\%CI 1,57-2,01)

Dari tabel IV terlihat obat yang terbanyak digunakan dari kategori obat kardiovaskuler adalah amlodipin terbanyak digunakan $30,47 \%$ (163 pasien) diikuti bisoprolol sebanyak $12,71 \%$ (68 pasien). Amlodipin merupakan antihipertensi golongan penghambat kanal kalsium dihidropiridin. Amlodipin bekerja langsung pada pembuluh darah sehingga dapat menyebabkan vasodilatasi. Efek samping dari penggunaan amlodipin adalah hipotensi postural yang dapat menyebabkan jatuh pada lansia ${ }^{20}$. Bisoprolol merupakan obat golongan penghambat reseptor beta. Pada suatu uji metanalisis obat golongan tersebut justru dapat menurunkan risiko jatuh pada lansia dengan OR 0,88 (95\%CI 0,80-0,97) ${ }^{18}$.

Obat dari kategori susunan saraf pusat yang banyak digunakan adalah gabapentin sebanyak $18,88 \%$ (101 pasien), diikuti diazepam sebesar $9,35 \%$ (50 pasien), dan amitriptilin sebesar 7,66\% (41 pasien). Hasil ini 
sejalan dengan penelitian sebelumnya dimana ketiga obat tersebut merupakan obat yang banyak digunakan ${ }^{21,22}$.

Pada lansia mengalami perubahan farmakokinetik dan farmakodinamik berupa penurunan fungsi organ pengeliminasi, peningkatan permeabilitas darah otak, dan juga peningkatan sensitivitas reseptor di susunan saraf pusat. Oleh karena itu pasien lansia lebih sensitif terhadap obat-obat yang bekerja pada susunan saraf pusat seperti gabapentin ${ }^{23}$. Gabapentin (N03AX12) termasuk dalam golongan antiepilepsi lainnya ${ }^{24}$. Obat ini bersifat lipofilik sehingga dengan mudah melewati sawar darah otak. Mekasnisme aksi dari gabapentin antara lain berikatan dengan subunit $\alpha$-kanal kalsium voltage-dependent, sehingga menghambat masuknya kalsium dan mencegah keluarnya neurotransmiter eksitatori25,26. Selain itu, pemakaian gabapentin meningkatkan kadar GABA dalam otak sebesar $55,7 \% \%^{27}$. Dari mekanisme tersebut maka muncul efek samping antara lain pusing (19\%), mengantuk (14\%) dan gangguan keseimbangan (14\%), yang potensial menyebabkan jatuh ${ }^{28,29}$.

Diazepam merupakan obat golongan benzodiazepin yang dapat menyebabkan sedasi, pusing, penurunan fungsi neuromuskular, dan gangguan kognitif ${ }^{2}$. Diazepam diperlukan pada pasien lansia untuk mengatasi gangguan cemas, gangguan tidur, maupun sebagai kombinasi untuk terapi nyeri neuropatik. Diazepam merupakan obat golongan benzodiazpepin dengan metabolit yang beraksi panjang dengan waktu paruh eliminasi 44-48 jam. Benzodiazepin berikatan dengan reseptor benzodiazepin pada saraf post sinap GABA (Gama Amino Butiric Acid) di sistem saraf pusat. Saat reseptor benzodiazepin ditempati akan mempotensiasi peningkatan permeabilitas membran terhadap ion klorida yang bersifat negatif, sehingga menyebabkan hiperpolarisasi dan stabilisasi sehingga timbul efek tenang dan relaksan otot. Efek dari diazepam yang berpotensi menyebabkan jatuh adalah sedasi, pusing, penurunan fungsi neuromuscular, dan gangguan kognitif ${ }^{2}, 20$.
Amitriptilin dan gabapentin sering diperlukan pada lansia untuk indikasi nyeri neuropati28,30,31. Amitriptiline (N06AA09) merupakan obat antidepresan penghambat reuptake monoamin non-selektif ${ }^{24}$. Mekanisme aksi sebagai antinyeri dari amitriptilin melalui penghambatan reuptake monoamin sehingga meningkatkan neurotransmiter sinaptik dan memfasilitasi sistem kontrol nyeri endogen ${ }^{32}$. Amitriptilin efektif untuk nyeri neuropati namun 55\% pasien setidaknya mengalami satu efek samping, dengan risiko relative sebesar 1,5 $(95 \% \text { CI } 1,3-1,8)^{30}$. Efek samping yang potensial sebagai risiko jatuh adalah sedasi, mengatuk di siang hari, hipotensi orthostatik, dan $\operatorname{aritmia}^{31}$.

Diharapkan hasil penelitian ini dapat dijadikan pijakan untuk penelitian-penelitian selanjutnya. Penelitian selanjutnya diharapkan dapat menghubungkan penggunaan obat-obat yang berpotensi terhadap jatuh dengan kejadian jatuh pada lansia.

\section{KESIMPULAN}

Dari hasil penelitian ini diketahui penggunaan obat yang menyebabkan risiko jatuh pada lansia cukup tinggi 65,42\% (343 pasien). Golongan fall risk mediicnes (FRM) yang sering diresepkan adalah antihipertensi $52,71 \%$ (282 pasien), antikonvulsan 20,19\% (108 pasien), dan benzodiazepin 10,47\% (56 pasien). Jumlah pengguna 1 obat FRM sebesar 24,86\% (133 pasien) diikuti 2 obat sebesar $19,07 \%$ (102 pasien), dimana sebesar $17,57 \%$ (94 pasien) mempunyai nilai medication fall risk score (MFRS) yang tinggi $(\geq 6)$ sehingga perlu dipertimbangkan risiko dan manfaat penggunaannya untuk mencegah kejadian jatuh pada lansia.

\section{UCAPAN TERIMAKASIH}

Fakultas Farmasi sebagai sponsor dana, RSUD dr. Soedono Madiun, dan RSUD Kota Madiun.

\section{DAFTAR PUSTAKA}

1. Badan Pusat Statistik. Statistik Penduduk Lanjut Usia 2017. Jakarta: Badan Pusat 
Statistik; 2018.

2. Yoshida S. A Global Report on Falls Prevention- Epidemiology of Falls. Ageing Life Course, Fam Community Heal WHO. 2007:1-40.

3. Paolo C., Loredana G., Gianfranco S., et al., Unexplained Falls Are Frequent in Patients with Fall-Related Injury Admitted to Orthopaedic Wards: The UFO Study (Unexplained Falls in Older Patients). Curr Gerontol Geriatr Res. 2013;2013:1-6.

4. Ganz DA., Huang C., Saliba D., Berlowitz D., Lukas CV. Preventing Falls in Hospitals A Toolkit for Improving Quality of Care. Agency Healthc Res Qual. 2013;13-0015-EF.

5. Musich S., Wang SS., Ruiz J., et al., FallsRelated Drug Use and Risk of Falls Among Older Adults : A Study in a US Medicare Population. Drugs Aging. 2017;34(7):555-565.

6. Badan Pusat Statistik Jawa Timur. Profil Penduduk Lanjut Usia Provinsi Jawa Timur 2017. (BPS Provinsi Jawa Timur, ed.). Surabaya: PT Sinar Multi Indoprinting; 2018.

7. Carral JMC., Ayán C., Sturzinger L., Gonzalez G. Relationship Between Body Mass Index and Static and Dynamic Balance in Active and Inactive Older Adults. J Geriatr Phys Ther. 2018:16.

8. Mitchell RJ., Lord SR., Harvey LA., Close JCT. Associations between obesity and overweight and fall risk, health status and quality of life in older people. Aust N Z J Public Health. 2014;(July 2013):13-18.

9. Alshammari SA., Alhassan AM., Aldawsari MA., Bazuhair FO., Alotaibi FK. Falls among elderly and its relation with their health problems and surrounding environmental factors in Riyadh. I Family Community Med. 2018;25(1):29-34.

10. Bao W., $\mathrm{Hu}$ D., Shi X., et al., Comorbidity increased the risk of falls in Chinese older adults: a cross- sectional study. 2017;10(7):10753-10763.

11. Kementerian Kesehatan Republik Indonesia. Hasil Utama RISKESDAS 2018.; 2018.

12. Kementerian Kesehatan Republik Indonesia. Infodatin Hipertensi.; 2017.

13. Kusumawaty J., Hidayat N., Ginanjar E. Hubungan Jenis Kelamin dengan Intensitas Hipertensi pada Lansia di Wilayah Factors Related Events Sex with Hypertension in Elderly Work Area Health District Lakbok Ciamis. Mutiara Med. 2016;16(2):46-51.

14. Leipzig RM., Cumming RG. Drugs and Falls in Older People: A Systematic Review and Meta-analysis: I. Psychotropic Drugs. J Am Geriatr Soc. 1999;47:30-39.

15. Bloch F., Thibaud M., Dugué B., Brèque C., Kemoun G. Psychotropic Drugs and Falls in the Elderly People: Updated Literature Review and Meta-Analysis. J Aging Health. 2011;23(2):329-346.

16. J.C. W., K.J. R., M.O. W., et al., Metaanalysis of the impact of 9 medication classes on falls in elderly persons. Arch Intern Med. 2009;169(21):1952-1960. http://archinte.amaassn.org/cgi/reprint/169/21/1952\%5Cnh ttp://ovidsp.ovid.com/ovidweb.cgi?T=J S\&PAGE $=$ reference\&D=emed9\&NEWS $=\mathrm{N} \& A N=2010011449$.

17. Pratt NL., Ramsay EN. Association Between Use of Multiple Psychoactive Medicines and Hospitalization for Falls : Retrospective Analysis of a Large Healthcare Claim Database. Drug Saf. 2014;37:529-535.

18. Vries $M$ de., Seppala LJ., Daams JG., Glind EMM van de, Masud T, Velde N van der. Fall-Risk-Increasing Drugs: A Systematic Review and MetaAnalysis:I. Cardiovascular Drugs. JAMDA. 2018:1-9.

19. Masud TM., Frost M., Ryg J., et al., Central nervous system medications and falls risk in men aged $60-75$ years : the Study on Male Osteoporosis and Aging ( SOMA ). Age Ageing. 
2013;42(August 2012):121-124.

20. Wolter Kluwer. Lexicomp Drug Information Handbook. 26th ed. American Pharmacist Association; 2018.

21. Mustafidah N. Hubungan Penggunaan Obat Psikoaktif Dengan Risiko Jatuh Pada Pasien Geriatri Rawat Jalan Di Klinik Saraf Rumah Sakit Madiun. 2019.

22. Annisa L. Hubungan Penggunaan Obat Psikoaktif dengan Risiko Jatuh pada Pasien Lanjut Usia di Klinik Penyakit Dalam Rumah Sakit Madiun. 2019.

23. Lee JK., Mendoza DM., Mohler MJ., Lee EM. Geriatrics. In: Chisholm-Burns MA, Schwinghammer TL, Wells BG, Malone PM, Kolesar JM, DiPiro JT, eds. Pharmacotherapy Principle and Practice. 4th ed. United State: McGraw-Hill Education; 2016:7-18.

24. WHO. Guideline for ATC Classification and DDD Assignment 2018.; 2018. ttps://www.whocc.no/atc_ddd_index/.

25. Gee NS., Brown JP., Dissanayake VUK., Offord J., Thurlow R., Woodruff GN. The Novel Anticonvulsant Drug , Gabapentin ( Neurontin ), Binds to the alfa2gama Subunit of a Calcium Channel. J Biol Chem. 1996;271(10):57685776.

ttps://www.whocc.no/atc_ddd_index/.

26. Bockbrader HN., Wesche D., Miller R., Chapel S., Janiczek N., Burger P. A Comparison of the Pharmacokinetics and Pharmacodynamics of Pregabalin and Gabapentin. Clin Pharmacokinet. 2010;49(10):661-669.

27. Cai K., Nanga RPR., Lamprou L., et al.,
The Impact of Gabapentin Administration on Brain GABA and Glutamate Concentrations: A 7T $1 \mathrm{H}-$ MRS Study. Neuropsychopharmacology. 2012;37(13):2764-2771.

28. Wiffen PJ., Derry S., Bell RF., et al., Gabapentin for chronic neuropathic pain in adults ( Review ). Cochrane Database Syst Rev. 2017;(6):10-13.

29. Fife TD., Sirven J. Antiepileptic drugs and their impact on balance. Aging health. 2005;1(1):147-155. www.futuremedicine.com.

30. Ra M., Derry S., Aldington D., et al., Amitriptyline for neuropathic pain in adults ( Review ) Amitriptyline for neuropathic pain in adults. Cochrane Database Syst Rev. 2017;(7):2015-2017.

31. Kamerman PR., Finnerup NB., Lima L De., et al., Gabapentin for neuropathic pain: An application to the 21st meeting of the WHO Expert Committee on Selection and Use of Essential Medicines for the inclusion of gabapentin on the WHO Model List of Essential Medicines. In: An Application to the 21st Meet- Ing of TheWHO Expert Committee on Selection and Use of Essential Medicines for the Inclusion of Gabapentin on TheWHO Model List of Essential Medicines. ; 2016:1-50.

32. Lawson K. A Brief Review of the Pharmacology of Amitriptyline and Clinical Outcomes in Treating Fibromyalgia. Biomedicines. 2017;5(24):1-12. 